\title{
Imagining Ocean Science: Public Engagement Using Real-time Streaming and Connection
}

\author{
CARLIE WIENER
}

Schmidt Ocean Institute

Ocean science was once completed in remote regions with little public engagement, however, this has changed with a growing number of scientists and institutions looking to expand their reach. Scientists now bring in local community members, artists, students and scientists using data visualization, technology, and the arts. These mechanisms enable broader understanding of the ocean and offer students and learners new opportunities to engage and train in ocean sciences. The goal of these efforts are to make the public rethink the way marine science is shared and break down the complexities of ocean research. This session will share innovative projects that are being conducted and presented in remote regions using real-time efforts. 